Article

\title{
Two Methods for Increased Specificity and Sensitivity in Loop-Mediated Isothermal Amplification
}

\author{
De-Guo Wang ${ }^{1, *}$, Jeffrey D. Brewster ${ }^{2}$, Moushumi Paul ${ }^{2}$ and Peggy M. Tomasula ${ }^{2}$ \\ 1 Henan Postdoctoral Research Base, Food and Bioengineering College, Xuchang University, \\ Xuchang 461000, China \\ 2 Eastern Regional Research Center, Agricultural Research Service, United States Department of \\ Agriculture, Wyndmoor, PA 19038, USA; E-Mails: Jeffrey.Brewster@ARS.USDA.GOV (J.D.B.); \\ Moushumi.Paul@ARS.USDA.GOV (M.P.); Peggy.Tomasula@ARS.USDA.GOV (P.M.T.) \\ * Author to whom correspondence should be addressed; E-Mail: wangdg666@126.com; \\ Tel./Fax: +86-374-296-8907.
}

Academic Editor: Derek J. McPhee

Received: 1 February 2015 / Accepted: 1 April 2015 / Published: 7 April 2015

\begin{abstract}
The technique of loop-mediated isothermal amplification (LAMP) utilizes four (or six) primers targeting six (or eight) regions within a fairly small segment of a genome for amplification, with concentration higher than that used in traditional PCR methods. The high concentrations of primers used leads to an increased likelihood of non-specific amplification induced by primer dimers. In this study, a set of LAMP primers were designed targeting the prfA gene sequence of Listeria monocytogenes, and dimethyl sulfoxide (DMSO) as well as Touchdown LAMP were employed to increase the sensitivity and specificity of the LAMP reactions. The results indicate that the detection limit of this novel LAMP assay with the newly designed primers and additives was $10 \mathrm{fg}$ per reaction, which is ten-fold more sensitive than a commercial Isothermal Amplification Kit and hundred-fold more sensitive than previously reported LAMP assays. This highly sensitive LAMP assay has been shown to detect 11 strains of Listeria monocytogenes, and does not detect other Listeria species (including Listeria innocua and Listeria invanovii), providing some advantages in specificity over commercial Isothermal Amplification Kits and previously reported LAMP assay.
\end{abstract}


Keywords: loop-mediated isothermal amplification (LAMP); non-specific amplification; dimethyl sulfoxide (DMSO); Touchdown LAMP

\section{Introduction}

Loop-mediated isothermal amplification, developed and reported by Notomi et al., in 2000 [1], can specifically, sensitively and rapidly amplify nucleic acids with two pairs of primers recognizing 6 independent sequences of a target gene under isothermal conditions. Moreover, Nagamine et al., has advanced the method by putting forward loop primers that accelerate the LAMP reaction [2]. Therefore, the LAMP assay theoretically has the advantage of specificity, selectivity, and rapidity over polymerase chain reaction (PCR) [3,4], nucleic acid sequence based amplification (NASBA) [5,6], strand displacement amplification (SDA) [7], rolling circle amplification (RCA) [8], helicase dependent amplification (HDA) [9], and cross-priming amplification assay (CPA) [10,11]. For practical application of LAMP as well as reduction of the rate of false positive results in LAMP reactions, most researches currently focus on development of closed-tube detection to reduce aerosol pollution and cross pollution, which include the use of turbidity [12], SYBR Green I [13], PicoGreen [14], GelRed $^{\mathrm{TM}}$ [15,16], lateral flow dipstick [17], hydroxynaphthol blue dye [18], malachite green [19], microfluidic chips and GMR sensors as well as calcein used by Eiken Chemical Co., Ltd [20,21]. However, there is still no report studying non-specific amplification and cause of false positive results in LAMP reactions at present.

The objective of this paper is to study the cause and limit the rate of false positive results in LAMP reactions targeting L. monocytogenes as well as to increase the specificity and sensitivity of these LAMP reactions using DMSO and Touchdown LAMP.

\section{Results and Discussion}

\subsection{Non-Specific Amplification of LAMP Primers Targeting hlyA of L. Monocytogenes}

Although there were only two primers, non-specific amplification occurred in the isothermal amplification of four primer combinations out of seven combinations, and it was more obvious in the reaction of three primer combinations ( $h l y \mathrm{~A}-\mathrm{FIP}+h l y \mathrm{~A}-\mathrm{LF}, h l y \mathrm{~A}-\mathrm{FIP}+h l y \mathrm{~A}-\mathrm{LB}, h l y \mathrm{~A}-\mathrm{FIP}+h l y \mathrm{~A}-\mathrm{B} 3)$, as Table 1 shown. Analysis on the three combinations indicated that they had the common situation that 3-4 bases at 3' end of both primers had two complementary sequences on a same primer, and such situation had been avoided when LAMP primers for prfA of L. monocytogenes were designed and screened in this study. Moreover, it was proved by the experiment that non-specific amplification caused by primer dimers was one reason for false positive results of LAMP. 
Table 1. Non-specific amplification of varying loop-mediated isothermal amplification (LAMP) primer combination.

\begin{tabular}{|c|c|c|c|c|c|c|c|}
\hline $\begin{array}{c}\text { Results of } \\
\text { Amplification }\end{array}$ & $\begin{array}{c}\text { hlyA-FIP + } \\
\operatorname{hlyA-LF}\end{array}$ & $\begin{array}{c}h l y \mathrm{~A}-\mathrm{FIP}+ \\
h l y \mathrm{~A}-\mathrm{LB}\end{array}$ & $\begin{array}{c}\text { hlyA-FIP + } \\
\text { hlyA-F3 }\end{array}$ & $\begin{array}{c}h l y \mathrm{~A}-\mathrm{FIP}+ \\
h l y \mathrm{~A}-\mathrm{B} 3\end{array}$ & $\begin{array}{c}h l y \mathrm{~A}-\mathrm{BIP}+ \\
h l y \mathrm{~A}-\mathrm{F} 3\end{array}$ & $\begin{array}{c}h l y \mathrm{~A}-\mathrm{BIP}+ \\
h l y \mathrm{~A}-\mathrm{LF}\end{array}$ & $\begin{array}{c}h l y \mathrm{~A}-\mathrm{F} 3+ \\
\operatorname{hly} \mathrm{A}-\mathrm{B} 3\end{array}$ \\
\hline $\begin{array}{l}\text { Non-specific } \\
\text { Amplification }\end{array}$ & $4 / 4$ & $4 / 4$ & $1 / 4$ & $4 / 4$ & $0 / 4$ & $0 / 4$ & $0 / 4$ \\
\hline
\end{tabular}

\subsection{Optimization of DMSO Concentration}

The LAMP reaction mixtures containing varying concentrations of DMSO were heated at $57{ }^{\circ} \mathrm{C}$ for $60 \mathrm{~min}$ (30 s per cycle), as indicated in Figure 1. When 5\% DMSO was added, the detection time for $1 \mathrm{pg}$ L. monocytogenes genomic DNA was less than $25 \mathrm{~min}$; however, one of the two negative controls amplified as well. The $\mathrm{T}_{\mathrm{m}}$ value and melt curve were obviously different from those of the positive controls, and were therefore as attributed to non-specific amplification, which may be caused by partial complementation among primers of LAMP. The detection time with 10\% DMSO was slightly longer than with $7.5 \%$. Overall, the results showed that the lower concentration of DMSO does not inhibit non-specific amplification while the higher concentration of DMSO may inhibit the activity of Bst 2.0 WarmStart DNA polymerase, and therefore, 7.5\% DMSO was determined to be the optimal among these three concentrations.

\subsection{Selection of Reaction Temperature for LAMP}

$7.5 \%$ DMSO was added to LAMP reaction mixtures and the reactions were carried out at varying temperatures for $60 \mathrm{~min}$, as shown in Table 2. With a reaction temperature of $61{ }^{\circ} \mathrm{C}$, only one of two positive controls ( $1 \mathrm{pg}$ L. monocytogenes genomic DNA) was detected. The threshold time obtained using a reaction temperature of $57^{\circ} \mathrm{C}$ was shorter than that obtained using $53{ }^{\circ} \mathrm{C}$ reaction temperature and slightly shorter than that obtained using the other temperatures. Therefore, $57^{\circ} \mathrm{C}$ was chosen as the most suitable reaction temperature.

Table 2. Non-specific amplification of varying LAMP primer combination.

\begin{tabular}{|c|c|c|c|c|c|}
\hline $\mathrm{PC} / \mathrm{NC}$ & $\begin{array}{l}\text { Threshold Time } \\
\text { at } 61^{\circ} \mathrm{C}(\mathrm{min})\end{array}$ & $\begin{array}{l}\text { Threshold Time } \\
\text { at } 59^{\circ} \mathrm{C}(\mathrm{min})\end{array}$ & $\begin{array}{l}\text { Threshold Time } \\
\text { at } 57^{\circ} \mathrm{C}(\mathrm{min})\end{array}$ & $\begin{array}{l}\text { Threshold Time } \\
\text { at } 55^{\circ} \mathrm{C}(\mathrm{min})\end{array}$ & $\begin{array}{l}\text { Threshold Time } \\
\text { at } 53^{\circ} \mathrm{C}(\mathrm{min})\end{array}$ \\
\hline \multirow{2}{*}{$\begin{array}{c}\text { Positive Control } \\
\text { (1 pg DNA) }\end{array}$} & 42 & 28 & 26 & 28 & 36 \\
\hline & undetermined & 32 & 26 & 27 & 56 \\
\hline \multirow{2}{*}{ Negative Control } & undetermined & undetermined & undetermined & undetermined & undetermined \\
\hline & undetermined & undetermined & undetermined & undetermined & undetermined \\
\hline
\end{tabular}

\subsection{Detection Limit Comparison}

The optimized LAMP reaction conditions were used with the conventional LAMP methodology with a serial dilution of $L$. monocytogenes DNA template was and these mixtures were heated at $57{ }^{\circ} \mathrm{C}$ for $60 \mathrm{~min}$. As shown in Table 3, the detection limit of the optimized reaction mixture using the conventional LAMP technique was found to be $1000 \mathrm{fg}$ L. monocytogenes DNA template. 

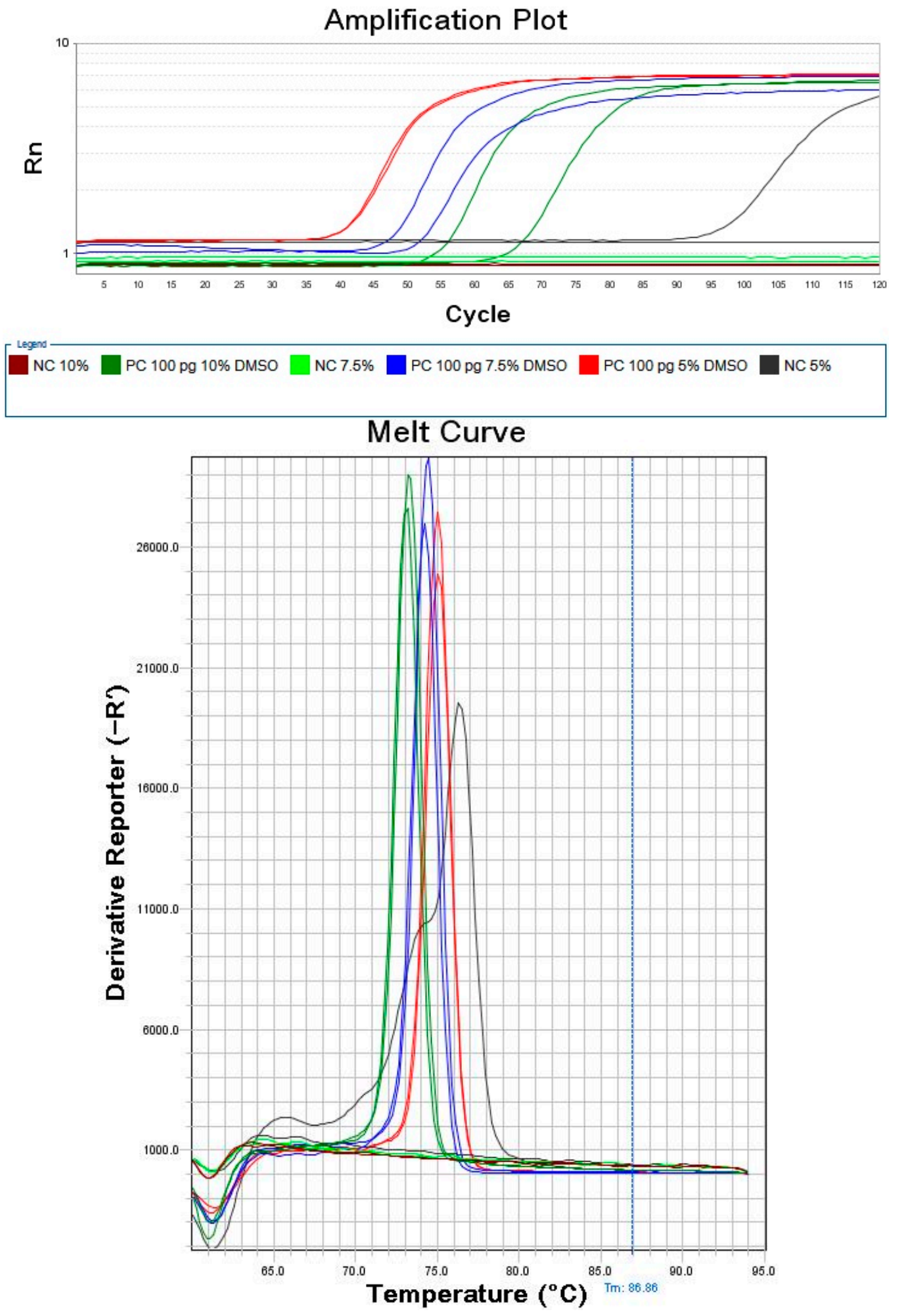

Figure 1. Amplification plot and melt curve of LAMP with varying concentrations of DMSO. The plot type was Rn vs. Cycle, and the graph type was log with $1 \times$ SYBR Green I added and $1 \times$ ROX as Reference Dye; the plot of Melt Curve was Derivative Reporter. 
Table 3. Sensitivity determination with different LAMP methods.

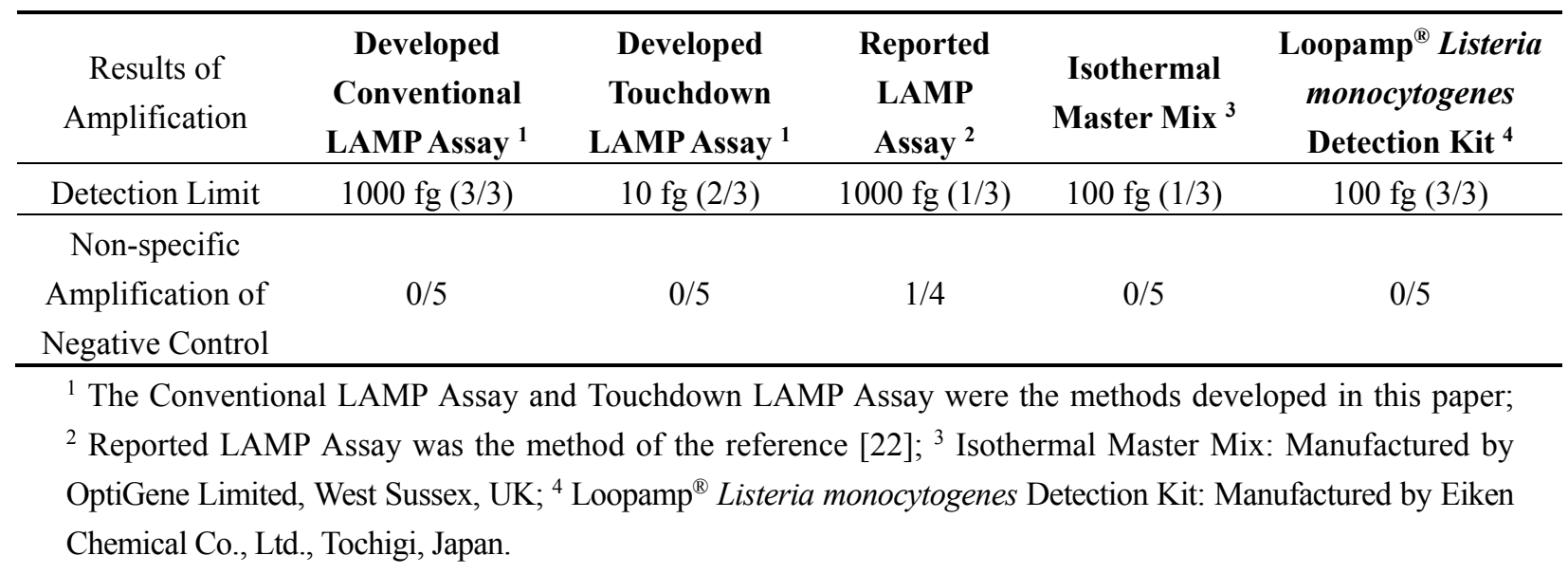

The optimized LAMP mixture was used with the Touchdown methodology to detect a serial dilution of L. monocytogenes DNA template. After the mixtures were preheated at $95{ }^{\circ} \mathrm{C}$ for 5 min and Bst 2.0 WarmStart DNA polymerase (New England Biolabs, Beverly, MA, USA) were added, they were heated at $63{ }^{\circ} \mathrm{C}$ for $5 \mathrm{~min}$, at $61^{\circ} \mathrm{C}$ for $5 \mathrm{~min}$, at $59{ }^{\circ} \mathrm{C}$ for $5 \mathrm{~min}$ and then at $57^{\circ} \mathrm{C}$ for $60 \mathrm{~min}$, and, as indicated in Table 3, the sensitivity of Touchdown LAMP was found to be $10 \mathrm{fg}$ of L. monocytogenes DNA. Therefore comparing these identical reaction mixtures in the conventional LAMP assay and the Touchdown LAMP assay shows that the Touchdown LAMP method increases the overall sensitivity of LAMP assay.

The detection limit of the original reported LAMP method by Tang, et al (Tang method) tested using $1000 \mathrm{fg}$ L. monocytogenes DNA template, as well. Only one of 3 positives controls amplified using these conditions. Moreover, one of four negative controls showed non-specific amplification, as reported in Table 3.

Sensitivity of both the Isothermal Master Mix using our own designed LAMP primers as well as the Loopamp ${ }^{\circledR}$ Listeria monocytogenes Detection Kit to detect L. monocytogenes was tested. The results indicate that the detection limit of both commercial LAMP kits is $100 \mathrm{fg}$ L. monocytogenes DNA template per reaction, as shown in Table 4.

Therefore, the sensitivity of the newly developed LAMP assay presented here was ten-fold higher than that obtained using the commercial Isothermal Amplification Kits and hundred-fold higher than the originally reported Tang LAMP assay.

\subsection{Assaying Selectivity}

This newly developed LAMP assay was tested with 11 Listeria monocytogenes strains (10 stereotypes) and as shown in Table 4, all 11 were successfully detected. The assay was also tested with five other Listeria species. In the initial experiment, Listeria invanovii ATCC49954 was falsely detected and one of three reactions amplified, while the other species had negative results. The experiment with $L$. invanovii ATCC49954 was repeated four times and all four repeated reactions were negative. Therefore, the initial false positive result may have been caused by slight aerosol pollution of DNA templates. 
Table 4. Specificity determination with different LAMP methods.

\begin{tabular}{|c|c|c|c|c|}
\hline Bacterial Strain (Serotype) & $\begin{array}{l}\text { Developed Touchdown } \\
\text { LAMP Assay }{ }^{1} \\
\end{array}$ & $\begin{array}{c}\text { Reported } \\
\text { LAMP Assay }{ }^{2} \\
\end{array}$ & $\begin{array}{c}\text { Isothermal } \\
\text { Master Mix }{ }^{3}\end{array}$ & $\begin{array}{c}\text { Loopamp }^{\circledR} \text { Listeria } \\
\text { monocytogenes Detection } \text { Kit }^{4}\end{array}$ \\
\hline $\begin{array}{l}\text { Listeria monocytogenes } \\
\quad \mathrm{J} 1-225(4 \mathrm{~b})\end{array}$ & $3 / 3$ & $2 / 2$ & $3 / 3$ & $3 / 3$ \\
\hline $\begin{array}{l}\text { Listeria monocytogenes } \\
\quad \mathrm{J} 2-020(1 / 2 \mathrm{a})\end{array}$ & $3 / 3$ & $2 / 2$ & $3 / 3$ & $3 / 3$ \\
\hline $\begin{array}{l}\text { Listeria monocytogenes } \\
\qquad \mathrm{J} 2-064(1 / 2 \mathrm{~b})\end{array}$ & $3 / 3$ & $1 / 2$ & $3 / 3$ & $3 / 3$ \\
\hline $\begin{array}{l}\text { Listeria monocytogenes } \\
\qquad \mathrm{J} 1-169(3 \mathrm{~b})\end{array}$ & $3 / 3$ & $2 / 2$ & $3 / 3$ & $3 / 3$ \\
\hline $\begin{array}{l}\text { Listeria monocytogenes } \\
\qquad \mathrm{J} 1-049(3 \mathrm{c})\end{array}$ & $3 / 3$ & $2 / 2$ & $3 / 3$ & $3 / 3$ \\
\hline $\begin{array}{l}\text { Listeria monocytogenes } \\
\text { M1-004 (N/A) }\end{array}$ & $3 / 3$ & $2 / 2$ & $3 / 3$ & $3 / 3$ \\
\hline $\begin{array}{l}\text { Listeria monocytogenes } \\
\qquad \mathrm{J} 1-094(1 / 2 \mathrm{c})\end{array}$ & $3 / 3$ & $2 / 2$ & $3 / 3$ & $3 / 3$ \\
\hline $\begin{array}{l}\text { Listeria monocytogenes } \\
\qquad \mathrm{C} 1-115 \text { (3a) }\end{array}$ & $3 / 3$ & $2 / 2$ & $3 / 3$ & $3 / 3$ \\
\hline $\begin{array}{l}\text { Listeria monocytogenes } \\
\quad \mathrm{J} 1-031(4 \mathrm{a})\end{array}$ & $3 / 3$ & $2 / 2$ & $5 / 7$ & $3 / 3$ \\
\hline $\begin{array}{l}\text { Listeria monocytogenes } \\
\qquad \mathrm{W} 1-110(4 \mathrm{c})\end{array}$ & $3 / 3$ & $2 / 2$ & $3 / 3$ & $3 / 3$ \\
\hline $\begin{array}{l}\text { Listeria monocytogenes } \\
\text { ATCC19115 (4b) }\end{array}$ & $3 / 3$ & $1 / 2$ & $3 / 3$ & $3 / 3$ \\
\hline Listeria innосиа АТСС51742 & $0 / 3$ & $0 / 2$ & $0 / 3$ & $1 / 7$ \\
\hline $\begin{array}{l}\text { Listeria invanovii } \\
\text { ATCC49954 }\end{array}$ & $1 / 7$ & $0 / 2$ & $0 / 3$ & $0 / 3$ \\
\hline Salmonella typhimuriam & $0 / 3$ & $0 / 2$ & $0 / 3$ & $0 / 3$ \\
\hline $\begin{array}{c}\text { Salmonella enterica serotype } \\
\text { Newport }\end{array}$ & $0 / 3$ & $0 / 2$ & $0 / 3$ & $0 / 3$ \\
\hline Escherichia coli O157:H7 933 & $0 / 3$ & $0 / 2$ & $0 / 3$ & $0 / 3$ \\
\hline Negative Controls & $0 / 7$ & $0 / 3$ & $1 / 6$ & $1 / 8$ \\
\hline
\end{tabular}

${ }^{1}$ The Conventional LAMP Assay and Touchdown LAMP Assay were the methods developed in this paper;

${ }^{2}$ Reported LAMP Assay was the method of the reference [22]; ${ }^{3}$ Isothermal Master Mix: Manufactured by OptiGene Limited; ${ }^{4}$ Loopamp ${ }^{\circledR}$ Listeria monocytogenes Detection Kit: Manufactured by Eiken Chemical Co., Ltd.

While the reported LAMP assay can favorably differentiate Listeria monocytogenes from other Listeria species, the detection time was quite long. The amplification time originally reported by Tang, et al. was $40 \mathrm{~min}$ [19]; however, the optimized LAMP assay required an extended amplification time of $50 \mathrm{~min}$, and even with the lengthy reaction time, two strains (Listeria monocytogenes J2-064 (stereotype: 1/2b) and Listeria monocytogenes ATCC19115 (stereotype: 4b) were not detected, as shown in Table 4. Extending the amplification time further to $1 \mathrm{~h}$, led to non-specific amplification of negative controls. 
The two commercial LAMP Kits were able to distinguish Listeria monocytogenes from other Listeria species. There were, however, two negative controls that exhibited non-specific amplification, and, sometimes, L. monocytogenes J1-031 (stereotype: 4a) was not detected, as shown in Table 4.

Therefore, the newly developed LAMP assay presented here can detect 10 stereotypes of Listeria monocytogenes selectively while not detecting other Listeria species (including Listeria innocua and Listeria invanovii), and had some advantages over commercial Isothermal Amplification Kit and the original Tang LAMP assay in specificity.

\section{Experimental Section}

\subsection{Primer Design}

The LAMP primers targeting specific gene hlyA of Listeria monocytogenes reported by Tang, et al., are used for studying non-specific amplification of LAMP [22], as shown in Table 5.

Table 5. Primers for detecting prfA of L. monocytogenes with LAMP.

\begin{tabular}{cc}
\hline Primer & Sequence (5'-3') \\
\hline hlyA-FIP & CGTGTTTCTTTTCGATTGGCGTCTTTTTTCATCCATGGCACCACC \\
hlyA-BIP & CCACGGAGATGCAGTGACAAATGTTTTGGATTTCTTCTTTTTCTCCACAAC \\
hlyA-F3 & TTGCGCAACAAACTGAAGC \\
hlyA-B3 & GCTTTTACGAGAGCACCTGG \\
hlyA-LF & TAGGACTTGCAGGCGGAGATG \\
hlyA-LB & GCCAAGAAAAGGTTACAAAGATGG \\
prfA-FIP & CCGCTCCTTTTTAATTCGTAAAACTTTTTAAAACGTGTCCTTAACTCTCTC \\
prfA-BIP & ATCATGGTAATAGCTTTTCAGGCTTTTTTTGAAGTTTTCTTCCCCG \\
prfA-F3 & AACGTATAATTTAGTTCCCACAT \\
prfA-B3 & GGGTCTTTTTGGCTTGTGTA \\
prfA-LF & TTAAGCCACCTACAACTAATCTGAC \\
prfA-LB & CATTTCACTATGACGGTAAAAGCAG \\
\hline
\end{tabular}

Targeting the specific gene prfA (GenBank Locus: AY512430.1) of L. monocytogenes, a set of LAMP primers were designed and selected with PrimerExplorer 4 and Oligo 7 according to the reported methodology [23], and are listed in Table 5.

\subsection{Non-Specific Amplification of LAMP Primers}

The isothermal amplification was performed in a total $25 \mu \mathrm{L}$ reaction mixture containing $1.25 \mathrm{mM}$ dNTPs, $1 \mathrm{M}$ betaine (Sigma-Aldrich Corp, St Louis, MO, USA), $20 \mathrm{mM}$ Tris-HCl (pH 8.8), $10 \mathrm{mM}$ $\mathrm{KCl}, 10 \mathrm{mM}\left(\mathrm{NH}_{4}\right)_{2} \mathrm{SO}_{4}, 6 \mathrm{mM} \mathrm{MgSO} 4,0.1 \%$ Triton X-100 and 8 units of Bst 2.0 WarmStart DNA polymerase (New England Biolabs, Beverly, MA, USA) according to the report of Tang, et al. [22], different combination of LAMP primers targeting hlyA were added into different tube, as listed in Table 2, the concentrations of hlyA-FIP, hlyA-BIP, hlyA-F3, hlyA-B3, hlyA-LF, and hlyA-LB were $0.8 \mathrm{mM}, 0.8 \mathrm{mM}, 0.4 \mathrm{mM}, 0.4 \mathrm{mM}, 0.1 \mathrm{mM}$ and $0.1 \mathrm{mM}$, respectively, and DNA template was not added for determination of non-specific amplification. The amplification reaction was performed at $65{ }^{\circ} \mathrm{C}$ for $50 \mathrm{~min}$ in StepOne ${ }^{\mathrm{TM}}$ System (Applied Biosystems, Foster City, CA, USA). 


\subsection{Optimization of DMSO Concentration}

LAMP was performed in $10 \mu \mathrm{L}$ reaction mixture containing $0.8 \mathrm{mM}$ each of prfA-FIP and prfA-BIP, $0.2 \mathrm{mM}$ each of prfA-F3 and prfA-B3, $0.4 \mathrm{mM}$ each of prfA-LF and prfA-LB, $1.0 \mathrm{mM}$ dNTPs, $20 \mathrm{mM}$ Tris- $\mathrm{HCl}$ (pH 8.8), $10 \mathrm{mM} \mathrm{KCl}, 10 \mathrm{mM}\left(\mathrm{NH}_{4}\right)_{2} \mathrm{SO}_{4}, 6 \mathrm{mM} \mathrm{MgSO}_{4}, 0.1 \%$ Triton X-100, 3.2 units of the Bst 2.0 WarmStart DNA polymerase (New England Biolabs, Beverly, MA, USA), $1 \times$ EvaGreen, $1 \times$ Rox, 1 pg L. monocytogenes DNA template [1,22]. 5\%, 7.5\% and 10\% DMSO were added into different reaction tubes. LAMP was carried out at $57{ }^{\circ} \mathrm{C}$ for $60 \mathrm{~min}$ and a melt curve was obtained using a StepOne ${ }^{\mathrm{TM}}$ System.

\subsection{Selection of Reaction Temperature for LAMP}

LAMP was performed as above in a $10 \mu \mathrm{L}$ reaction mixture containing $1 \mathrm{pg}$ L. monocytogenes DNA template as well as the optimized concentration DMSO at $61,59,57,55$ and $53{ }^{\circ} \mathrm{C}$ for 60 min, and a melt curve was obtained using a StepOne ${ }^{\mathrm{TM}}$ System.

\subsection{Sensitivity Comparison of Our Developed LAMP Assay, Reported LAMP Assay and Commercial Isothermal Amplification Kit}

The optimized LAMP mixture was combined with serial dilutions of DNA template of Listeria monocytogenes ranging from 1 to $1000 \mathrm{fg}$, and the reaction mixtures were heated at selected temperature $57{ }^{\circ} \mathrm{C}$ for $60 \mathrm{~min}$ in StepOne ${ }^{\mathrm{TM}}$ System, and the detection limit of conventional LAMP was determined.

In the case of Touchdown LAMP, the reaction mixture was preheated at $95{ }^{\circ} \mathrm{C}$ for $5 \mathrm{~min}$. After $5 \mathrm{~min}$, Bst 2.0 WarmStart DNA Polymerase (Large Fragment) was added and the reaction mixture was heated at temperatures $6{ }^{\circ} \mathrm{C}$ higher than selected temperature for $5 \mathrm{~min}$, at temperature of $4{ }^{\circ} \mathrm{C}$ higher than selected temperature for $5 \mathrm{~min}$, at temperature of $2{ }^{\circ} \mathrm{C}$ higher than selected temperature for $5 \mathrm{~min}$ and then at selected temperature for $60 \mathrm{~min}$, and the sensitivity of Touchdown LAMP was determined and compared with that of conventional LAMP.

For comparison, the detection limit of the reported method by Tang, et al., (Tang LAMP assay) was determined by carrying out LAMP reactions according to the conditions specified in their publication [22].

Isothermal Master Mix and Loopamp ${ }^{\circledR}$ Listeria monocytogenes Detection Kits were purchased from OptiGene Limited (West Sussex, UK) and Eiken Chemical Co., Ltd (Tochigi, Japan), respectively, and LAMP was carried out according to the manufacturers' instructions using a set of serially diluted DNA template of L. monocytogenes ranging from 1 to $1000 \mathrm{fg}$.

\subsection{Specificity Determination of Optimized Touchdown LAMP assay, Tang LAMP Assay and Commercial Isothermal Amplification Kit}

Eleven strains of L. monocytogenes (different stereotype) and 5 other Listeria species (including L. innocua and L. invanovii) were used for the specificity study (Table 4). Listeria strains were cultured overnight at $37^{\circ} \mathrm{C}$ in Difco ${ }^{\mathrm{TM}}$ Buffered Listeria Enrichment Broth Base (Becton, Dickinson and Company, San Jose, CA, USA) and the others in Luria-Bertani (LB) broth. DNA from these pure cultures was extracted according to the manufacturer's handbook of DNeasy ${ }^{\circledR}$ Blood and Tissue Kit (QIAGEN 
LTD, North Manchester, UK), and these DNA templates was used for determining the specificity of the optimized Touchdown LAMP assay, the Tang LAMP assay and the LAMP assay utilizing the commercial Isothermal Amplification Kit. The amount of DNA template used is 1 pg per reaction.

\section{Conclusions}

It is difficult to avoid primer dimers and non-specific amplification when couple numerous sets of primers are used in LAMP assays. This is especially true when the concentrations of primers, $\mathrm{Mg}^{2+}$, dNTPs and DNA Polymerase in reaction mixtures are as high as those used in Real-time PCR. The concentrations of these 4 factors must be strictly controlled to avoid non-specific amplification in real-time PCR [24] as well as LAMP reactions. There are instances in which standard PCR amplification reaction conditions do not produce acceptable results. Addition of DMSO and use of Touchdown temperature conditions have been used improve PCR results. We investigate these approaches for the first time for optimization of LAMP reactions. Unfortunately, with the information presently available it is not possible to predict which enhancing agent is best for any particular target. But DMSO has been frequently used in this capacity [25]. The results presented here using DMSO in LAMP reaction mixtures indicate that, DMSO can increase amplification with LAMP at low concentration and can inhibit activity of Bst 2.0 WarmStart DNA polymerase. We had tried to enhance the reaction of LAMP with betaine, Tetramethylammonium chloride, tetramethylene sulfoxide, and formamide, but their effect was not as good as that of DMSO, because of the limitation of length, no more tautology here. While DMSO may not necessarily be the best enhancing agent [26,27], i.e., the manufacturer of the commercial Isothermal Amplification Kit used in this experiment may have found some favorable enhancing agent, but their reagents are proprietary, and DMSO served to decrease non-specific amplification in the specific experiments presented here.

Touchdown PCR offered a simple and rapid means to optimize PCRs, increasing specificity, sensitivity and yield, without the need for lengthy reaction times and/or the redesigning of primers [28,29]. Touchdown LAMP, compared to conventional LAMP methods, results in increased sensitivity and yield of LAMP. This improvement may be due to the high temperature inhibiting the formation of primer dimers and promoting the correct combination of primers and template. The biggest advantage of LAMP is that the reaction can be performed isothermally, and people argue all the time that all we need is a simple water bath for the rapid detection, so the advantage may be compromised by the developed Touchdown LAMP assay, we made such efforts here just to reveal or verify the main cause for false positive results of LAMP and inspire people to modify and improve LAMP technology, my colleagues and I have also been looking for a more suitable method, which can not only keep the advantage but also improve the sensitivity and specificity of LAMP.

In summary, non-specific amplification was a limiting factor in the applicability of the LAMP methodology. A few different options to eliminate this issue have been reported here to successfully selectively and sensitively detect L. monocytogenes. Designing ideal primers, additives such as DMSO, and method modifications such as Touchdown LAMP may be favorable alternatives for increased specificity and sensitivity in LAMP in other applications as well. 


\section{Acknowledgments}

The authors would like to acknowledge the China Scholarship Council. This work was supported by Natural Science Foundation of China (31172331), NSFC-Henan Talent Training Joint Foundation (U1204330), Project for Scientific Research and Innovation Team of Henan Universities (15IRTSTHN016), Foundation of Henan Province for Excellent Young Teachers of Colleges and Universities (2012GGJS-172), Project of Xuchang University for Outstanding Young Backbone Teachers, and Training Project for Outstanding Youth Backbone Personnel of Xuchang University.

\section{Author Contributions}

D.W. performed the experiments. M.P. wrote the paper. J.B. and P.T. designed the experiments.

\section{Conflicts of Interest}

The authors declare no conflict of interest.

\section{References}

1. Notomi, T.; Okayama, H.; Masubuchi, H.; Yonekawa, T.; Watanabe, K.; Amino, N.; Hase, T. Loop-mediated isothermal amplification of DNA. Nucl. Acid. Res. 2000, 28, e63, doi:10.1093/nar/28.12.e63.

2. Nagamine, K.; Hase, T.; Notomi, T. Accelerated reaction by loop-mediated isothermal amplification using loop primers. Mol. Cell. Probes 2002, 16, 223-229.

3. Saiki, R.K.; Scharf, S.; Faloona, F.; Mullis, K.B.; Horn, G.T.; Erlich, H.A.; Arnheim, N. Enzymatic amplification of $\beta$-globin genomic sequences and restriction site analysis for diagnosis of sickle cell anemia. Science 1985, 230, 1350-1354.

4. Saiki, R.K.; Gelfand, D.H.; Stoffel, S.; Scharf, S.J.; Higuchi, R.; Horn, G.T.; Mullis, K.B.; Erlich, H.A. Primer-Directed Enzymatic Amplification of DNA with a Thermostable DNA Polymerase. Science 1998, 239, 487-491.

5. Compton, J. Nucleic acid sequence-based amplification. Nature 1991, 350, 91-92.

6. Fahy, E.; Kwoh, D.Y.; Gingeras, T.R. Self-sustained sequence replication (3SR): An isothermal transcription-based amplification system alternative to PCR. Genome. Res. 1991, 1, 25-33.

7. Walker, G.T.; Fraiser, M.S.; Schram, J.L.; Little, M.C.; Nadeau, J.G.; Malinowski, D.P. Strand displacement amplification-an isothermal, in vitro DNA amplification technique. Nucl. Acid Res. 1992, 20, 1691-1696.

8. Lizardi, P.M.; Huang, X.; Zhu, Z.; Bray-Ward, P.; Thomas, D.C.; Ward, D.C. Mutation detection and single-molecule counting using isothermal rolling-circle amplification. Nat. Genet. 1998, 19, 225-232.

9. Vincent, M.; Yan, X.; Kong, H. Helicase-dependent isothermal DNA amplification. EMBO Rep. 2004, 5, 795-800.

10. Fang, R.; Li, X.; Hu, L.; You, Q.; Li, J.; Wu, J.; Xu, P.; Zhong, H.; Luo, Y.; Mei, J.; Gao, Q. Cross-priming amplification for rapid detection of Mycobacterium tuberculosis in sputum specimens. J. Clin. Microbiol. 2009, 47, 845-847. 
11. Woźniakowski, G.; Niczyporuk, J.S.; Samorek-Salamonowicz, E.; Gaweł, A. The development and evaluation of cross-priming amplification for the detection of avian reovirus. J. Appl. Microbiol. 2015, 118, 528-536.

12. Haridas, D.V.; Pillai, D.; Manojkumar, B.; Nair, C.M.; Sherief, P.M. Optimisation of reverse transcriptase loop-mediated isothermal amplification assay for rapid detection of Macrobrachium rosenbergii noda virus and extra small virus in Macrobrachium rosenbergii. J. Virol. Methods 2010, 167, 61-67.

13. Perera, N.; Aonuma, H.; Yoshimura, A.; Teramoto, T.; Iseki, H.; Nelson, B.; Igarashi, I.; Yagi, T.; Fukumoto, S.; Kanuka, H. Rapid identification of virus-carrying mosquitoes using reverse transcription-loop-mediated isothermal amplification. J. Virol. Methods 2009, 156, 32-36.

14. Ren, X.F.; Li, P.C. Development of reverse transcription loop-mediated isothermal amplification for rapid detection of porcine epidemic diarrhea virus. Virus Genes 2011, 42, 229-235.

15. Woźniakowski, G.; Kozdruń, W.; Samorek-Salamonowicz, E. Loop-mediated isothermal amplification for the detection of goose circovirus. Virol. J. 2012, 9, 110, doi:10.1186/1743-422X-9-110.

16. Wassermann, M.; Mackenstedt, U.; Romig, T. A loop-mediated isothermal amplification (LAMP) method for the identification of species within the Echinococcus granulosus complex. Vet. Pathol. 2014, 200, 97-103.

17. Prompamorn, P.; Sithigorngul, P.; Rukpratanporn, S.; Longyant, S.; Sridulyakul, P.; Chaivisuthangkura, P. The development of loop-mediated isothermal amplification combined with lateral flow dipstick for detection of Vibrio parahaemolyticus. Lett. Appl. Microbiol. 2011, 52, 344-351.

18. Cardoso, T.C.; Ferrari, H.F.; Bregano, L.C.; Silva-Frade, C.; Rosa, A.C.; Andrade, A.L. Visual detection of turkey coronavirus RNA in tissues and feces by reverse-transcription loop-mediated isothermal amplification (RT-LAMP) with hydroxynaphthol blue dye. Mol. Cell. Probes 2010, 24, 415-417.

19. Nzelu, C.O.; Gomez, E.A.; Cáceres, A.G.; Sakurai, T.; Martini-Robles, L.; Uezato, H.; Mimori, T.; Katakura, K.; Hashiguchi, Y.; Kato, H. Development of a loop-mediated isothermal amplification method for rapid mass-screening of sand flies for Leishmania infection. Acta Trop. 2014, 132, 1-6.

20. Zhi, X.; Deng, M.; Yang, H.; Gao, G.; Wang, K.; Fu, H.L.; Zhang, Y.X.; Chen, D.; Cui, D.X. A novel HBV genotypes detecting system combined with microfluidic chip, loop-mediated isothermal amplification and GMR sensors. Biosens. Bioelectron. 2014, 54, 372-377.

21. Tong, Q.B.; Chen, R.; Zhang, Y.; Yang, G.J.; Takashi, K.; Rieko, F.S.; Lou, D.; Yang, K.; Wen, L.Y.; Lu, S.H.; et al. A new surveillance and response tool: Risk map of infected Oncomelania hupensis detected by Loop-mediated isothermal amplification (LAMP) from pooled samples. Acta Trop. 2015, 141, 170-177.

22. Tang, M.J.; Zhou, S.; Zhang, X.Y.; Pu, J.H.; Ge, Q.L.; Tang, X.J.; Gao, Y.S. Rapid and Sensitive Detection of Listeria monocytogenes by Loop-Mediated Isothermal Amplification. Curr. Microbiol. 2011, 63, 511-516.

23. Li, S.L.; zhang, X.B.; Wang, D.G.; Kuang, Y.Y.; Xu, Y.G. Simple and Rapid Method for Detecting Foodborne Shigella by a Loop-mediated Isothermal Amplification. J. Rapid Methods Autom. Microbiol. 2009, 17, 465-475. 
24. Higuchi, R.; Fockler, C.; Dollinger, G.; Watson, R. Kinetic PCR analysis: Real-time monitoring of DNA amplification reactions. Biotechnology 1993, 11, 1026-1030.

25. Frackman, S.; Kobs, G.; Simpson, D.; Storts, D. Betaine and DMSO: Enhancing Agents for PCR. Promega Notes 1998, 65, 27-29.

26. Hung, T.; Mak, K.; Fong, K. A specificity enhancer for polymerase chain reaction. Nucl. Acid Res. 1990, 18, 4953, doi:10.1093/nar/18.16.4953.

27. Bachmann, B.; Lüke, W.; Hunsmann, G. Improvement of PCR amplified DNA sequencing with the aid of detergents. Nucl. Acid Res. 1990, 18, 1309, doi:10.1093/nar/18.5.1309.

28. Korbie, D.J.; Mattick, J.S. Touchdown PCR for increased specificity and sensitivity in PCR amplification. Nat. Protoc. 2008, 3, 1452-1456.

29. Don, R.H.; Cox, P.T.; Wainwright, B.J.; Baker, K.; Mattick, J.S. "Touchdown" PCR to circumvent spurious priming during gene amplification. Nucl. Acid Res. 1991, 19, 4008, doi:10.1093/nar/19.14.4008.

Sample Availability: Not available.

(C) 2015 by the authors; licensee MDPI, Basel, Switzerland. This article is an open access article distributed under the terms and conditions of the Creative Commons Attribution license (http://creativecommons.org/licenses/by/4.0/). 